\title{
Peripapillary choroidal thickness in healthy Turkish subjects
}

\author{
This article was published in the following Dove Press journal: \\ Clinical Ophthalmology \\ 30 July 2015 \\ Number of times this article has been viewed
}

\section{Hulya Erbagci' \\ Burak Oren ${ }^{2}$ \\ Seydi Okumus ${ }^{3}$ \\ Serhat Kenan ${ }^{3}$ \\ Pelin Celemler ${ }^{3}$ \\ Ibrahim Erbagci ${ }^{3}$}

'Department of Anatomy, Medical Faculty, Zirve University Emine Bahattin Nakiboglu, Gaziantep, ${ }^{2}$ Department of Ophthalmology, Kilis State Hospital, Kilis,

${ }^{3}$ Department of Ophthalmology, Faculty of Medicine, University of Gaziantep, Gaziantep, Turkey
Correspondence: Burak Oren Department of Ophthalmology, Kilis State Hospital, Kilis, Turkey Tel +90348 8I35202 ext I I45 Email burakoren@windowslive.com
Aim: The objective of the study reported here was to investigate the normal peripapillary choroidal thickness (CT), measured by enhanced depth imaging optical coherence tomography (EDI-OCT), in healthy Turkish volunteers.

Materials and methods: In this prospective cross-sectional study, 57 eyes of 57 healthy Turkish subjects were enrolled. Each participant underwent a comprehensive ophthalmic examination and peripapillary CT measurement using EDI-OCT.

Results: The mean age of the 25 female and 32 male patients in the study was $30.9 \pm 10.6$ years (range, 18-56 years). The mean peripapillary CT at the superior, inferior, nasal, and temporal sites was $225 \pm 57,183 \pm 47,220 \pm 57$, and $233 \pm 59 \mu \mathrm{m}$, respectively. The inferior peripapillary CT value was significantly lower than the peripapillary CT values $(P<0.001$ for all), whereas no significant differences were found between the superior, nasal, and temporal peripapillary CT values.

Conclusion: The findings of the study revealed that Turkish people had significantly lower peripapillary CT values in the inferior quadrant than in the superior, nasal, and temporal quadrants.

Keywords: peripapillary choroidal thickness, enhanced depth imaging optical coherence tomography, EDI-OCT

\section{Introduction}

The choroid, a well-vascularized connective tissue, resides between the retina pigment epithelium and the sclera and extends from the ora serrata anteriorly to the optic nerve posteriorly. The choroid receives most of the ocular blood flow $(\sim 85 \%)$ and has one of the highest metabolic activities in the body. The physiological functions of the choroid include providing vascular supply to the anterior optic nerve head and retina, emmetropization, thermoregulation, and waste-product removal. ${ }^{1,2}$ Thus, a structurally and functionally healthy choroid plays an essential role in the function of the macula and peripapillary area.

The abnormal choroid has been associated with many macular diseases, such as age-related macular degeneration, central serous chorioretinopathy, diabetic retinopathy, Behçet's disease, and retinitis pigmentosa. ${ }^{3-7}$ Some previous studies have also reported that abnormal peripapillary choroidal blood supply may have a role in the development of glaucomatous optic neuropathy. ${ }^{8-10}$ In this respect, determination of peripapillary choroidal thickness (CT) in a healthy population may be helpful for displaying the pathological alterations in peripapillary areas, such as glaucoma, and might be a useful tool in clinical practice.

Until recently, the choroid could only be evaluated by indocyanine green angiography and ultrasonography. The development of spectral-domain optical coherence tomography has recently presented enhanced depth imaging optical coherence tomography 
(EDI-OCT), which allows in vivo examination and quantification of the choroid. ${ }^{11}$ The aim of the study reported here was to determine the normal peripapillary $\mathrm{CT}$, measured by EDI-OCT, in healthy Turkish volunteers.

\section{Materials and methods Study design and subjects}

This prospective cross-sectional study included 57 healthy Turkish subjects. Participants were recruited from the Gaziantep University School of Medicine Department of Ophthalmology between January and July 2014. The Ethics Committee of Gaziantep University School of Medicine approval and informed consent from all patients in accordance with the Declaration of Helsinki were obtained.

Each participant was subjected to comprehensive ophthalmic assessment, including visual acuity, refraction (using a KR 8900 refractometer [Topcon Corporation, Tokyo, Japan]), axial length (AL; with a Echoscan US-500 [Nidek Co, Ltd, Aichi, Japan]), slit-lamp biomicroscopy, intraocular pressure (with a Goldmann applanation tonometer), and dilated fundus examination. Exclusion criteria were diabetes mellitus; hypertension; and/or history of intraocular surgery, photodynamic therapy, transpupillary thermotherapy, focal laser treatment, ionizing radiation, uveitis, retinal disorders, glaucoma, amblyopia, high myopia, and/or poor image quality due to severe cataract.

\section{CT measurement}

The same clinician (BO) performed EDI-OCT imaging of all subjects in the morning (between 9 am and $12 \mathrm{pm}$ ) with Heidelberg Spectralis equipment (Heidelberg Engineering Inc, Heidelberg, Germany) as described previously: images, each comprising 100 scans, using the automatic averaging and eye tracking features, were obtained..$^{11}$ A $3.4 \mathrm{~mm}$ diameter peripapillary circle scan centered on the optic disc was used for retinal nerve-fiber layer measurement. CT was assessed manually from the retinal pigment epithelium to the inner face of the sclera, in the inferior, superior, nasal, and temporal quadrants. Two clinicians (BO and SK), who were masked to clinical patient data, measured the CT in all subjects and the mean value of the measurements was calculated. The eyes having more than $15 \%$ difference in measurement between the two clinicians were excluded from the study.

\section{Data analysis}

Statistical analysis was performed using SPSS software (v 22.0; IBM Corporation, Armonk, NY, USA). Only one eye per subject was randomly selected for statistical analysis.
Paired $t$-test was used to analyze CT at different locations. Pearson's correlation test was used to investigate the correlation between different variables. A $P$-value of less than 0.05 was considered statistically significant.

\section{Results}

A total of 57 eyes of 25 female and 32 male subjects were included in the study. The mean $( \pm \mathrm{SD})$ age of the subjects was $30.9 \pm 10.6$ years (range: $18-56$ ) (Figure 1). The mean AL was $23.35 \pm 0.75 \mathrm{~mm}$ (range: $21.48-25.01$ ). The mean spherical equivalent refraction error was $-0.42 \pm 1.06$ (range: -3.75 to 3.00$)$.

The mean peripapillary CT in the superior, inferior, nasal, and temporal quadrants was 225 $\pm 57,183 \pm 47,220 \pm 57$, and $233 \pm 59 \mu \mathrm{m}$, respectively (Figure 2). The inferior peripapillary CT value was significantly lower than superior, nasal, and temporal peripapillary $\mathrm{CT}$ values $(P<0.001$ for all $)$ (Table 1). There were no significant differences between the superior, nasal, and temporal peripapillary CT values (all $P>0.05$ ).

The correlation analyses between the superior, inferior, nasal, and temporal peripapillary CTs are shown in Table 2. All peripapillary CT values were significantly correlated with each other. There were no significant correlations between age, AL, or spherical equivalent, and each peripapillary $\mathrm{CT}$ measurement (Table 3).

When the data from the male and female groups were assessed as two different groups, the mean age was $33 \pm 12$ years in female subjects and $29 \pm 8$ years in male subjects $(P=0.198)$. The mean AL was $23.4 \pm 0.8 \mathrm{~mm}$ in male subjects and $23.2 \pm 0.7 \mathrm{~mm}$ in female subjects $(P=0.534)$. The mean peripapillary CT values of both sexes are shown in Table 4. Although each peripapillary CT value was thicker in males than in females, only the nasal peripapillary $\mathrm{CT}$ reached statistical significance $(P=0.016)$.

\section{Discussion}

The blood supply of the prelaminar area of the optic nerve head originates from the branches within the peripapillary choroid. The peripapillary choroid may have a role in several ocular pathologies such as pathological myopia and glaucoma. ${ }^{12-14}$ Evaluation of peripapillary CT can be used in elucidating physiopathological changes and monitoring of disease progression. Currently, EDI-OCT technology allows sensitive assessments of peripapillary and subfoveal CTs. To the best of our knowledge, we have been the first to report comprehensive data about the peripapillary CT of a healthy Turkish population by EDI-OCT. 


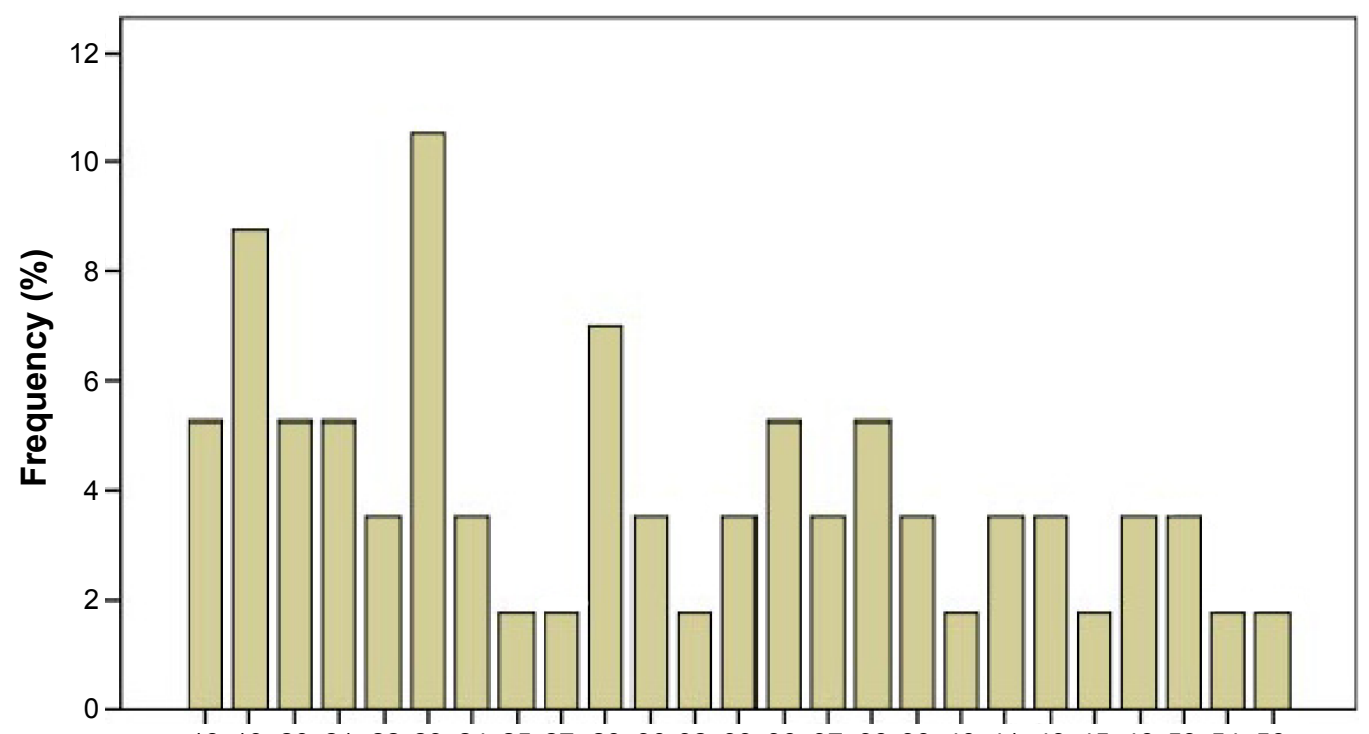

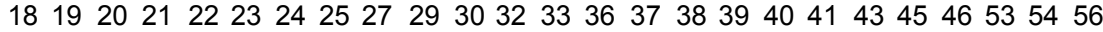

Age (years)

Figure I The distribution of age of all subjects.

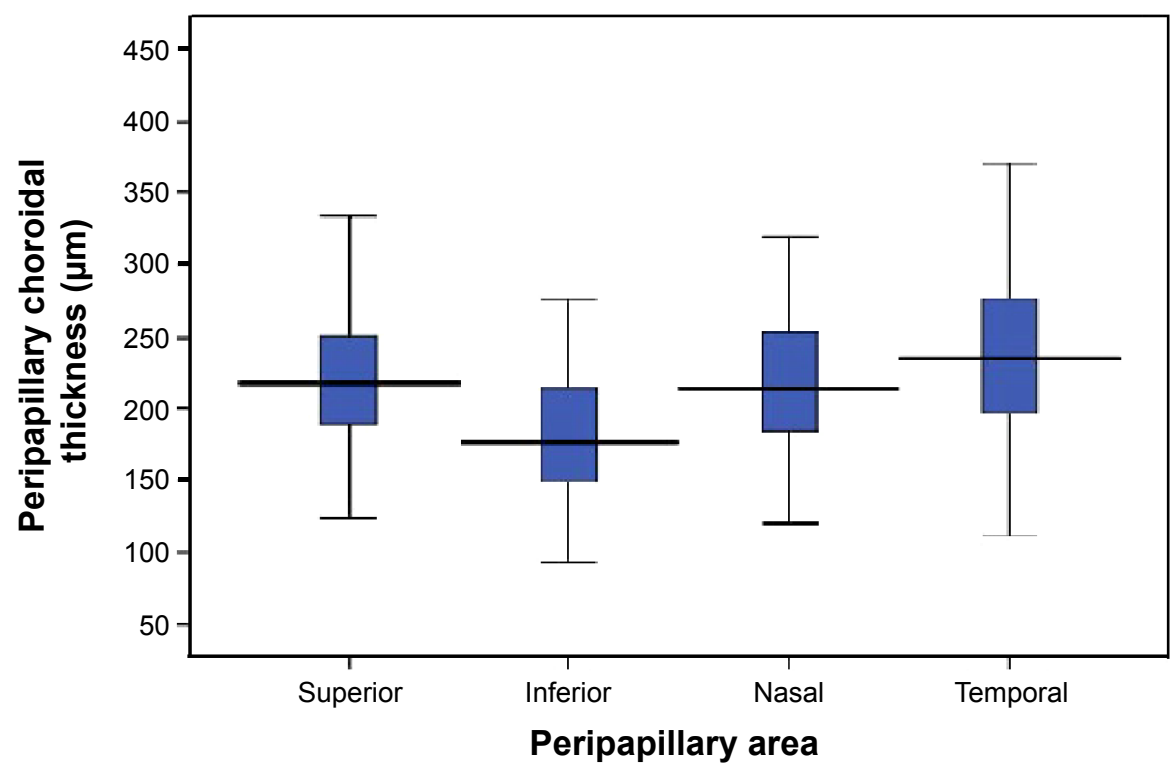

Figure 2 Box plot of peripapillary choroidal thickness values at each area measured by enhanced depth imaging optical coherence tomography.

Table I Mean peripapillary choroidal thickness values and pair-wise comparison of each peripapillary area

\begin{tabular}{|c|c|c|c|c|c|c|}
\hline \multicolumn{7}{|c|}{ Choroidal thickness, $\mu \mathrm{m}$} \\
\hline & & Superior & Inferior & & Nasal & Temporal \\
\hline Mean \pm SD & & $225 \pm 57$ & $183 \pm 47$ & & $220 \pm 57$ & $233 \pm 59$ \\
\hline Range & & $124-390$ & $93-327$ & & $120-408$ & $112-370$ \\
\hline \multicolumn{7}{|c|}{ Pair-wise comparison } \\
\hline & Sup-inf & Sup-bas & Sup-tem & Inf-nas & Inf-tem & Nas-tem \\
\hline$\overline{P^{*}}$ & $<0.001$ & 0.407 & 0.167 & $<0.001$ & $<0.001$ & 0.066 \\
\hline
\end{tabular}

Note: *Paired $t$-test.

Abbreviations: inf, inferior; sup, superior; nas, nasal; tem, temporal; bas, basal; SD, standard deviation. 
Table 2 Correlation analyses of peripapillary choroidal thickness values between each peripapillary area

\begin{tabular}{|c|c|c|c|c|c|}
\hline & & Superior & Inferior & Nasal & Temporal \\
\hline \multirow[t]{2}{*}{ Superior } & Correlation coefficient & & $0.766 * *$ & $0.755^{* *}$ & $0.690^{* *}$ \\
\hline & $p^{*}$ & & 0.000 & 0.000 & 0.000 \\
\hline \multirow[t]{2}{*}{ Inferior } & Correlation coefficient & $0.766 * *$ & & $0.735 * *$ & $0.722^{* *}$ \\
\hline & $p^{*}$ & 0.000 & & 0.000 & 0.000 \\
\hline \multirow[t]{2}{*}{ Nasal } & Correlation coefficient & $0.755^{* *}$ & $0.735^{* *}$ & & $0.603^{* *}$ \\
\hline & $p^{*}$ & 0.000 & 0.000 & & 0.000 \\
\hline \multirow[t]{2}{*}{ Temporal } & Correlation coefficient & 0.690 ** & $0.722^{* *}$ & $0.603 * *$ & \\
\hline & $p^{*}$ & 0.000 & 0.000 & 0.000 & \\
\hline
\end{tabular}

Notes: *Pearson's correlation test. **Correlation is significant at the 0.01 level (two tailed).

In our study, the peripapillary CT was thickest at the temporal quadrant, followed by the superior, nasal, and inferior regions. Our results are very similar to those in a study by Huang et al who evaluated the peripapillary CT in a healthy Chinese population. ${ }^{9}$ They determined same order for peripapillary $\mathrm{CT}$ thickness distributions. Tanabe et al found that the peripapillary CT was the thickest at the superior quadrant, followed by the temporal, nasal, and inferior regions in healthy subjects. ${ }^{15}$ Moreover, we found that only the inferior peripapillary CT showed statistically significant differences when compared with the temporal, superior, and nasal areas. Similarly, Huang et al and Tanabe et al indicated that the inferior peripapillary choroid was significantly thinner than all other sectors., ${ }^{9}, 15$

The most prominent finding of our and previous studies is the thinner $\mathrm{CT}$ in the inferior peripapillary area. Although the reason for this finding is not exactly known, embryological processes may have a role in inferior choroidal thinning. It has been found that the optic fissure, which is finally closed during ocular development, is placed in the inferior side of the optic cup. ${ }^{16}$ Future studies are needed to determine why the inferior peripapillary CT is significantly lower than the $\mathrm{CT}$ in other quadrants. Due to the prelaminar portion of the optic disk head being nourished by peripapillary choroidal circulation and the choroid being thinner in the inferior sector, the inferior optic disk may be more vulnerable to changes in the choroidal circulation flow. This claim is supported by previous studies that have shown that glaucoma influences the superior hemifield of the optic disc more frequently and more severely than the inferior hemifield of optic disc. ${ }^{8,15}$

Age and AL are well-known factors associated with CT in various studies. ${ }^{11,17,18}$ Studies have demonstrated that a decrease of nearly $11-13 \mu \mathrm{m}$ per decade occurs in peripapillary CT. ${ }^{9,19}$ On the other hand, Ho et al reported that the age of their subjects did not correlate with the peripapillary CT. ${ }^{20}$ Huang et al found no correlation between the peripapillary CT and AL. ${ }^{9}$ In this study, we did not find a correlation between the peripapillary $\mathrm{CT}$ and $\mathrm{AL}$ or age. This may be because of the small sample size used in this study. Also, when considering the sex factor, each of the peripapillary $\mathrm{CT}$ values was thicker in males than in females, but only the difference in nasal peripapillary CT between the two sexes was statistically significant.

\section{Limitations}

The present study has several limitations. The study was relatively small. Moreover, the Heidelberg Spectralis optical coherence tomography equipment does not provide automatic segmentation of the choroid; hence, all identifications of Bruch's membrane and the inner scleral border were conducted manually.

Table 3 Correlation analyses between peripapillary choroidal thickness values and age, axial length (AL), or spherical refraction (SR)

\begin{tabular}{llllll}
\hline & & Superior & Inferior & Nasal & Temporal \\
\hline Age & Correlation coefficient & -0.021 & -0.151 & -0.063 & -0.087 \\
& $P^{*}$ & 0.875 & 0.263 & 0.639 & 0.519 \\
AL, mm & Correlation coefficient & -0.002 & -0.154 & 0.025 & -0.200 \\
& $P^{*}$ & 0.986 & 0.254 & 0.852 & 0.136 \\
SR, D & Correlation coefficient & -0.114 & -0.023 & 0.037 & 0.115 \\
& $P^{*}$ & 0.397 & 0.868 & 0.783 & 0.393 \\
\hline
\end{tabular}

Note: *Pearson's correlation test.

Abbreviation: D, diopter. 
Table 4 Clinical features and choroidal thickness values of female and male subjects

\begin{tabular}{llll}
\hline Clinical feature & $\begin{array}{l}\text { Females, } \\
\text { mean } \pm \text { SD }\end{array}$ & $\begin{array}{l}\text { Males, } \\
\text { mean } \pm \text { SD }\end{array}$ & \\
\hline Age, years & $33 \pm 12$ & $29 \pm 8$ & 0.198 \\
AL, mm & $23.2 \pm 0.7$ & $23.4 \pm 0.8$ & 0.534 \\
SE, D & $-0.47 \pm 1.03$ & $-0.37 \pm 1.10$ & 0.738 \\
Choroidal thickness, $\mu \mathrm{m}$ & & & \\
$\quad$ Superior & $219 \pm 52$ & $229 \pm 60$ & 0.507 \\
$\quad$ Inferior & $169 \pm 40$ & $193 \pm 50$ & 0.058 \\
$\quad$ Nasal & $200 \pm 51$ & $236 \pm 57$ & 0.016 \\
$\quad$ Temporal & $224 \pm 58$ & $239 \pm 59$ & 0.346 \\
\hline
\end{tabular}

Note: *Independent Student's t-test.

Abbreviations: $A L$, axial length; $D$, diopter; SE, spherical equivalent.

\section{Conclusion}

The peripapillary CT in the Turkish population has some similarity to that in populations in previous studies. The findings of the study show that Turkish people have significantly lower peripapillary CT values in the inferior quadrant than in the superior, nasal, and temporal quadrants. Further studies are needed to elucidate the reason for this thinning in the inferior area.

\section{Disclosure}

The authors report no other conflicts of interest in this work.

\section{References}

1. Parver LM. Temperature modulating action of choroidal blood flow. Eye (Lond). 1991;5(Pt 2):181-185.

2. Wangsa-Wirawan ND, Linsenmeier RA. Retinal oxygen: fundamental and clinical aspects. Arch Ophthalmol. 2003;121(4):547-557.

3. Reiner A, Del Mar N, Zagvazdin Y, Li C, Fitzgerald ME. Age-related impairment in choroidal blood flow compensation for arterial blood pressure fluctuation in pigeons. Invest Ophthalmol Vis Sci. 2011; 52(10):7238-7247.

4. Coskun E, Gurler B, Pehlivan Y, et al. Enhanced depth imaging optical coherence tomography findings in Behçet disease. Ocul Immunol Inflamm. 2013;21(6):440-445.
5. Dhoot DS, Huo S, Yuan A, et al. Evaluation of choroidal thickness in retinitis pigmentosa using enhanced depth imaging optical coherence tomography. Br J Ophthalmol. 2013;97(1):66-69.

6. Kim SW, Oh J, Kwon SS, Yoo J, Huh K. Comparison of choroidal thickness among patients with healthy eyes, early age-related maculopathy, neovascular age-related macular degeneration, central serous chorioretinopathy, and polypoidal choroidal vasculopathy. Retina. 2011; 31(9):1904-1911.

7. Nagaoka T, Kitaya N, Sugawara R, et al. Alteration of choroidal circulation in the foveal region in patients with type 2 diabetes. $\mathrm{Br} J$ Ophthalmol. 2004;88(8):1060-1063.

8. Hirooka K, Tenkumo K, Fujiwara A, Baba T, Sato S, Shiraga F. Evaluation of peripapillary choroidal thickness in patients with normal-tension glaucoma. BMC Ophthalmol. 2012;12:29.

9. Huang W, Wang W, Zhou M, et al. Peripapillary choroidal thickness in healthy Chinese subjects. BMC Ophthalmol. 2013;10:13:23.

10. Hayreh SS. Blood supply of the optic nerve head and its role in optic atrophy, glaucoma, and oedema of the optic disc. Br J Ophthalmol. 1969; 53(11):721-748.

11. Coşkun E, Okumuş S, Gürler B, et al. Choroidal thickness in healthy Turkish subjects. Turk J Med Sci. 2014;44(1):56-61.

12. Yin ZQ, Vaegan, Millar TJ, Beaumont P, Sarks S. Widespread choroidal insufficiency in primary open-angle glaucoma. J Glaucoma. 1997; 6(1):23-32.

13. Spraul CW, Lang GE, Lang GK, Grossniklaus HE. Morphometric changes of the choriocapillaris and the choroidal vasculature in eyes with advanced glaucomatous changes. Vision Res. 2002;42(7):923-932.

14. Huang D, Swanson EA, Lin CP, et al. Optical coherence tomography. Science. 1991;254(5035):1178-1181.

15. Tanabe H, Ito $\mathrm{Y}$, Terasaki $\mathrm{H}$. Choroid is thinner in inferior region of optic disks of normal eyes. Retina. 2012;32(1):134-139.

16. Stoll C, Alembik Y, Dott B, Roth MP. Epidemiology of congenital eye malformations in 131,760 consecutive births. Ophthalmic Paediatr Genet. 1992;13(3):179-186.

17. Fujiwara T, Imamura Y, Margolis R, Slakter JS, Spaide RF. Enhanced depth imaging optical coherence tomography of the choroid in highly myopic eyes. Am J Ophthalmol. 2009;148(3):445-450.

18. Mwanza JC, Hochberg JT, Banitt MR, Feuer WJ, Budenz DL. Lack of association between glaucoma and macular choroidal thickness measured with enhanced depth-imaging optical coherence tomography. Invest Ophthalmol Vis Sci. 2011;52(6):3430-3435.

19. Park SC, De Moraes CG, Teng CC, Tello C, Liebmann JM, Ritch R. Enhanced depth imaging optical coherence tomography of deep optic nerve complex structures in glaucoma. Ophthalmology. 2012; 119(1):3-9.

20. Ho J, Branchini L, Regatieri C, Krishnan C, Fujimoto JG, Duker JS. Analysis of normal peripapillary choroidal thickness via spectral domain optical coherence tomography. Ophthalmology. 2011;118(10): 2001-2007.
Clinical Ophthalmology

\section{Publish your work in this journal}

Clinical Ophthalmology is an international, peer-reviewed journal covering all subspecialties within ophthalmology. Key topics include: Optometry; Visual science; Pharmacology and drug therapy in eye diseases; Basic Sciences; Primary and Secondary eye care; Patient Safety and Quality of Care Improvements. This journal is indexed on Submit your manuscript here: http://www.dovepress.com/clinical-ophthalmology-journal

\section{Dovepress}

PubMed Central and CAS, and is the official journal of The Society of Clinical Ophthalmology (SCO). The manuscript management system is completely online and includes a very quick and fair peer-review system, which is all easy to use. Visit http://www.dovepress.com/ testimonials.php to read real quotes from published authors. 